\title{
Contribution of VEGF polymorphism rs3025020 to short stature and hypertension in elderly Japanese individuals: a cross-sectional study
}

Yuji Shimizu ${ }^{1,2^{*}}$ D, Hirotomo Yamanashi ${ }^{3}$, Shin-Ya Kawashiri ${ }^{1}$, Kenichi Nobusue ${ }^{4}$, Fumiaki Nonaka ${ }^{4}$, Yuko Noguchi ${ }^{1}$, Yukiko Honda', Kazuhiko Arima ${ }^{5}$, Yasuyo Abe ${ }^{5}$, Yasuhiro Nagata ${ }^{1}$ and Takahiro Maeda ${ }^{3,4}$

\begin{abstract}
Background: Recently, short stature has been revealed to be positively associated with hypertension, possibly because this indicates lower activity of vascular maintenance, such as angiogenesis. Vascular endothelial growth factor (VEGF) polymorphism (rs3025020) plays an important role in the progression of angiogenesis and may be associated with both hypertension and hypertension-associated short stature.

Methods: A cross-sectional study of 1377 elderly Japanese individuals aged 60-89 years was conducted. Short stature was defined as the lowest tertile of height $(<160.8 \mathrm{~cm}$ for men and $<148.7 \mathrm{~cm}$ for women). Hypertension was defined as systolic blood pressure $\geq 140 \mathrm{mmHg}$ and/or diastolic blood pressure $\geq 90 \mathrm{mmHg}$ and/or antihypertensive medication use.

Results: Independent of known cardiovascular risk factors, short stature was found to be positively associated with hypertension; the fully adjusted odds ratio (OR) and 95\% confidence interval (CI) for hypertension were 1.51 (1.17, 1.96). With the reference group of carriers of the major allele of $\mathrm{rs} 3025020$, TT-homozygotes showed significantly lower OR for hypertension and short stature; the fully adjusted ORs (and 95\% Cls) were $0.60(0.41,0.90)$ for hypertension and $0.59(0.38,0.91)$ for short stature, respectively.

Conclusions: Angiogenesis-related genetic factor (rs3025020) is associated with hypertension and short stature, whereas short stature is positively associated with hypertension. Further investigation is necessary in this regard; the capacity for angiogenesis might partly explain the mechanism underlying the inverse association between height and hypertension.
\end{abstract}

Keyword: Height, Hypertension, rs3025020, Short stature, VEGF

\footnotetext{
* Correspondence: shimizuyuji@nagasaki-u.ac.jp

'Department of Community Medicine, Nagasaki University Graduate School of Biomedical Sciences, Nagasaki, Japan

${ }^{2}$ Department of Cardiovascular Disease Prevention, Osaka Center for Cancer and Cardiovascular Diseases Prevention, Osaka, Japan

Full list of author information is available at the end of the article
}

(c) The Author(s). 2021 Open Access This article is licensed under a Creative Commons Attribution 4.0 International License, which permits use, sharing, adaptation, distribution and reproduction in any medium or format, as long as you give appropriate credit to the original author(s) and the source, provide a link to the Creative Commons licence, and indicate if changes were made. The images or other third party material in this article are included in the article's Creative Commons licence, unless indicated otherwise in a credit line to the material. If material is not included in the article's Creative Commons licence and your intended use is not permitted by statutory regulation or exceeds the permitted use, you will need to obtain permission directly from the copyright holder. To view a copy of this licence, visit http://creativecommons.org/licenses/by/4.0/ The Creative Commons Public Domain Dedication waiver (http://creativecommons.org/publicdomain/zero/1.0/) applies to the data made available in this article, unless otherwise stated in a credit line to the data. 


\section{Introduction}

Recent studies have reported an inverse association between height and hypertension [1, 2]. However, the mechanisms underlying this inverse association have not yet been clarified.

Hematopoietic stem cells (CD34-positive cells) contribute to maintaining micro-circulation, partly by inducing angiogenesis [3]. Previously, we found that lower levels of circulating CD34-positive cells could elevate the risk of hypertension among elderly men [4, 5]. Since height could act as a factor for CD34-positive cell production in the elderly [6-8], the risk of hypertension for short stature might be caused by disruption of microcirculation associated with a deficiency of angiogenesis.

Vascular endothelial growth factor (VEGF) is a proangiogenic factor. Inhibition of VEGF causes hypertension [9]. The minor allele (T) of the VEGF polymorphism rs3025020 is reported to be positively associated with serum levels of VEGF [10] and therefore could play an important role in the association between short stature and hypertension.

Although hematopoietic activity suitably explains the association between short stature and hypertension [4$8]$, the genetic factor involved in this association has not been identified. Since understanding these genetic associations may help elucidate the mechanism underlying the association between hypertension and short stature, we conducted a cross-sectional study of 1377 elderly Japanese individuals aged 60-89 years who participated in an annual health checkup in 2017.

\section{Material and methods}

\section{Study population}

The methods that relate to present risk surveys, including genetic factors, have been previously described [11-13].

The study population comprised 1388 individuals (501 men and 887 women) aged 60-89 years, from Goto city, located in the western part of Japan, who participated in an annual health checkup conducted by the local government and directed by the Ministry of Health, Labor and Welfare in Japan in 2017. Participants without serum data $(n=11)$ were excluded from the analysis. Finally, 1377 elderly Japanese individuals (498 men and 879 women), with a mean age of 72.8 (standard deviation [SD]: 7.1), were enrolled in the study.

\section{Data collection and laboratory measurements}

Trained interviewers obtained the medical history and habitual status of each participant. Body weight and height were measured using an automatic body composition analyzer (BF-220; Tanita, Tokyo, Japan), from which the body mass index (BMI; $\mathrm{kg} / \mathrm{m}^{2}$ ) was calculated.
Fasting blood samples were collected. Concentrations of triglyceride (TG), HDL-cholesterol (HDLc), hemoglobin A1c (HbA1c), and creatinine were measured using standard laboratory procedures. All measurements were performed by SRL, Inc. (Tokyo, Japan). The glomerular filtration rate (GFR) was estimated using a recently adapted established method introduced by a working group of the Japanese Chronic Kidney Disease Initiative [14], which yielded an estimate of GFR (ml/ $\left.\min / 1.73 \mathrm{~m}^{2}\right)=194 \times($ serum creatinine [enzyme method $])^{-1.094} \times(\text { age })^{-0.287} \times(0.739$ for women $)$.

Genomic DNA was extracted from $2 \mathrm{~mL}$ of whole peripheral blood using Gene Prep Star NA-480 (Kurabo Industries Ltd., Osaka, Japan), and genotyping of singlenucleotide polymorphism (SNP) rs3025020 was conducted using TaqMan assays and a LightCycler 480 thermal cycling platform (Roche Diagnostics, Basel, Switzerland).

\section{Statistical analysis}

Characteristics of the study population by rs3025020 genotype are expressed as mean $\pm \mathrm{SD}$, except for prevalence of antihypertensive medication use and current smoker and daily drinker status. Significant differences involving rs3025020 genotypes were evaluated using analysis of variance.

Logistic regression models were used to calculate odds ratios (ORs) and 95\% confidence intervals (CIs) to determine associations between hypertension and short stature, between rs3025020 genotypes and hypertension, and between rs3025020 genotypes and short stature.

Two adjustment models were used. The first model (model 1) was adjusted only for sex and age. The second model (model 2) further included potential confounding factors known as cardiovascular risk factors, namely, BMI $\left(\mathrm{kg} / \mathrm{m}^{2}\right)$, smoking status (current, former, or never), drinking status (non, often, or daily), TG (mg/dL), HDLc $(\mathrm{mg} / \mathrm{dL}), \mathrm{HbA} 1 \mathrm{c}(\%)$, and GFR $\left(\mathrm{mL} / \mathrm{min} / 1.73 \mathrm{~m}^{2}\right)$.

We also evaluated the sex-adjusted values of height and the prevalence of short stature associated with the two categories of the rs3025020 genotype (carriers of the major allele and homozygous for the minor allele) using analysis of covariance.

The definition of short stature was the sex-specific lowest tertiles of height values $(<160.8 \mathrm{~cm}$ for men and $<148.7 \mathrm{~cm}$ for women). Hypertension was defined as systolic blood pressure $\geq 140 \mathrm{mmHg}$ and/or diastolic blood pressure $\geq 90 \mathrm{mmHg}$ and/or current antihypertensive medication use.

All statistical analyses were performed using the SAS system for Windows (v.9.4; SAS Inc., Cary, NC, USA). Values of $p<0.05$ were considered statistically significant. 
Table 1 Characteristics of study population by rs3025020 genotype

\begin{tabular}{|c|c|c|c|c|}
\hline & rs3025020 & & & $p$ \\
\hline & $\overline{(C / C)}$ & $(\mathrm{C} / \mathrm{T})$ & $(T / T)$ & \\
\hline No. of participants & 734 & 515 & 128 & \\
\hline Male, $\%$ & 38.0 & 33.8 & 35.2 & 0.301 \\
\hline Age & $72.5 \pm 7.0$ & $73.0 \pm 7.3$ & $73.1 \pm 6.9$ & 0.447 \\
\hline Height, cm & $155.6 \pm 8.8$ & $155.0 \pm 8.3$ & $156.1 \pm 7.6$ & 0.318 \\
\hline Systolic blood pressure, $\mathrm{mmHg}$ & $135 \pm 17$ & $135 \pm 18$ & $131 \pm 16$ & 0.044 \\
\hline Diastolic blood pressure, $\mathrm{mmHg}$ & $74 \pm 10$ & $74 \pm 11$ & $73 \pm 10$ & 0.369 \\
\hline Anti-hypertensive medication, \% & 43.5 & 42.3 & 36.7 & 0.363 \\
\hline Current smoker, \% & 17.3 & 15.3 & 14.8 & 0.944 \\
\hline Daily drinker, \% & 7.6 & 8.2 & 7.8 & 0.582 \\
\hline Body mass index (BMI), $\mathrm{kg} / \mathrm{m}^{2}$ & $22.6 \pm 3.3$ & $22.7 \pm 3.1$ & $22.6 \pm 3.3$ & 0.909 \\
\hline Triglycerides (TG), mg/dL & $106 \pm 57$ & $104 \pm 52$ & $95 \pm 59$ & 0.148 \\
\hline HDL-cholesterol (HDLc), mg/dL & $62 \pm 15$ & $62 \pm 16$ & $64 \pm 16$ & 0.377 \\
\hline Hemoglobin A1c (HbA1c), \% & $5.8 \pm 0.5$ & $5.8 \pm 0.6$ & $5.7 \pm 0.5$ & 0.679 \\
\hline Glomerular filtration rate (GFR), $\mathrm{mL} / \mathrm{min} / 1.73 \mathrm{~m}^{2}$ & $68.8 \pm 14.3$ & $69.0 \pm 14.0$ & $69.2 \pm 14.2$ & 0.934 \\
\hline
\end{tabular}

Values: mean \pm standard deviation

\section{Results}

\section{Study population characteristics}

Among the study population, the number of individuals with each rs3025020 genotype was 734 for CChomozygotes, 515 for heterozygotes, and 128 for TThomozygotes.

Table 1 presents the characteristics of the study population in relation to the rs3025020 genotype. The minor rs3025020 allele (T) was inversely associated with systolic blood pressure. Sex-specific height levels (mean $\pm \mathrm{SD}$ ) and (number of participants $[n]$ ) for each category among men were $163.7 \pm 6.2 \mathrm{~cm}(n=279)$ for homozygotes $(\mathrm{C} / \mathrm{C}), 163.2 \pm 6.2 \mathrm{~cm}(n=174)$ for heterozygotes $(\mathrm{C} / \mathrm{T})$, and $162.6 \pm 5.9 \mathrm{~cm}(n=45)$ for homozygotes $(\mathrm{T} / \mathrm{T})$ ( $\mathrm{p}=0.487$ ), and the corresponding values among women were $150.6 \pm 5.9 \mathrm{~cm}(n=455), 150.9 \pm 5.9 \mathrm{~cm}(n=341)$, and $152.6 \pm 5.9 \mathrm{~cm}(n=83)(p=0.015)$, respectively.

Table 2 Odds ratios (ORs) and 95\% confidence intervals (Cls) for hypertension in relation to short stature

\begin{tabular}{llll}
\hline & \multicolumn{2}{l}{ Short stature } & $\begin{array}{l}\boldsymbol{p} \\
\text { value }\end{array}$ \\
\cline { 2 - 3 } & $(-)$ & $(+)$ & \\
\hline No. of participants & 919 & 458 & \\
No. of cases (\%) & $503(54.7)$ & $311(67.9)$ & 0.007 \\
Model 1 & 1 & $1.40(1.10,1.79)$ & 0.002 \\
Model 2 & 1 & $1.51(1.17,1.96)$ &
\end{tabular}

Model 1: adjusted only for sex and age. Model 2: adjusted further for body mass index (BMI), smoking status, drinking status, triglycerides, HDL-cholesterol, $\mathrm{HbA} 1 \mathrm{c}$, and glomerular filtration rate (GFR). Short stature was defined as the lowest tertile of height ( $<160.8 \mathrm{~cm}$ for men and $<148.7 \mathrm{~cm}$ for women). Hypertension was defined as systolic blood pressure $\geq 140 \mathrm{mmHg}$ and/or diastolic blood pressure $\geq 90 \mathrm{mmHg}$ and/or taking anti-hypertensive medication

\section{Association between short stature and hypertension}

Among elderly Japanese individuals, short stature was found to be positively correlated with hypertension. This association was unaffected even after adjusting for known cardiovascular risk factors (Table 2).

\section{Association between rs3025020 genotype and hypertension}

Independent of known cardiovascular risk factors, the minor allele $(\mathrm{T})$ of rs3025020 was significantly inversely associated with hypertension. When we defined a reference group of carriers of the major allele $(\mathrm{C} / \mathrm{C}$ and $\mathrm{C} / \mathrm{T})$, homozygotes of the minor allele $(\mathrm{T} / \mathrm{T})$ exhibited significantly lower ORs for hypertension (Table 3 ).

\section{Association of sex-adjusted values of height and the prevalence of short stature for the rs3025020 genotype (carriers of the major allele and homozygous for the minor allele)}

Although no significant correlation between the sexadjusted values of height and two categories of rs3025020 (carriers of the major allele and homozygous for the minor allele) was observed, a significantly low prevalence of short stature was observed in individuals who were homozygous for the minor allele compared with those who were carriers of the major allele. The sex-adjusted values of height (least squared value \pm standard error) and prevalence of short stature (least squared value) were $155.3 \pm 0.2 \mathrm{~cm}$ and $34.1 \%$ for carriers of the major allele and $156.3 \pm 0.5 \mathrm{~cm}$ and $25.0 \%$ 
Table 3 Odds ratios (ORs) and 95\% confidence intervals (Cls) for hypertension in relation to rs3025020 genotypes

\begin{tabular}{|c|c|c|c|c|c|}
\hline & \multicolumn{3}{|l|}{ rs3025020 } & \multirow{2}{*}{$\begin{array}{l}p \\
\text { value }\end{array}$} & \multirow[t]{2}{*}{ Minor allele $(\mathrm{T})$} \\
\hline & $\overline{(C / C)}$ & $(\mathrm{C} / \mathrm{T})$ & $(T / T)$ & & \\
\hline No. of participants & 734 & 515 & 128 & & \\
\hline $\begin{array}{l}\text { No. of cases } \\
(\%)\end{array}$ & $442(60.2)$ & $309(60.0)$ & $63(49.2)$ & & \\
\hline \multirow[t]{2}{*}{ Model 1} & & & $0.61(0.42,0.89)$ & 0.010 & $0.84(0.71,0.997)$ \\
\hline & 1 & $0.96(0.76,1.22)$ & $0.61(0.41,0.89)$ & 0.046 & \\
\hline \multirow[t]{2}{*}{ Model 2} & & & $0.60(0.41,0.90)$ & 0.012 & $0.83(0.69,0.98)$ \\
\hline & 1 & $0.93(0.73,1.19)$ & $0.59(0.39,0.89)$ & 0.032 & \\
\hline
\end{tabular}

Model 1: adjusted only for sex and age. Model 2: adjusted further for body mass index (BMI), smoking status, drinking status, triglycerides, HDL-cholesterol, $\mathrm{HbA1C}$, and glomerular filtration rate (GFR). Hypertension was defined as systolic blood pressure $\geq 140 \mathrm{mmHg}$ and/or diastolic blood pressure $\geq 90 \mathrm{mmHg}$ and/or taking anti-hypertensive medication

for those homozygous for the minor allele $(p=0.090$ and 0.038$)$, respectively.

\section{Association between rs3025020 genotype and short stature}

Table 4 illustrates the association between rs3025020 genotype and short stature. Even though no significant association between the minor allele of rs3025020 and short stature was observed, an inverse tendency involving the two was noted. When we set a reference group of carriers of the major allele, homozygotes for the minor allele showed significantly lower ORs for short stature. This association was unchanged even after adjustment for known cardiovascular risk factors.

To test the sensitivity, we re-performed the main analyses using the sex-specific model and obtained essentially the same associations. For the association between short stature and hypertension, the age-adjusted ORs (and 95\% CIs) were $1.51(1.01,2.25)$ for men and 1.29 $(0.94,1.77)$ for women. The age-adjusted value of ORs (and 95\% CIs) of short stature with the rs3025020 genotype (using carriers of the major allele as a reference group) for homozygotes for the minor allele were 0.95 $(0.49,1.82)$ for men and $0.46(0.25,0.81)$ for women. The age-adjusted value of ORs (and 95\% CIs) of hypertension with the rs3025020 genotype (using carriers of the major allele as a reference group) for homozygotes for the minor allele were $0.52(0.28,0.97)$ for men and $0.68(0.42,1.09)$ for women.

\section{Discussion}

In this study, we demonstrated that homozygotes for the minor allele of the VEGF rs3025020 were found to be inversely associated with hypertension and short stature when compared with a reference group of carriers of the major allele; short stature was positively associated with hypertension.

Height is reported to be inversely associated with hypertension [1,2], which is consistent with our present results. However, the possible mechanisms underlying this association have not yet been clarified.

Disruption of microcirculation, which elevates peripheral vascular resistance, can cause hypertension [15]. Angiogenesis is one of the most important processes for maintaining microcirculation. Previously, we reported that height is positively associated with levels of hematopoietic stem cell (CD34-positive cells), which contribute to angiogenesis among elderly Japanese men [3, 6-8]. Since hematopoietic bone marrow activity declines with age [16-18] and absolute bone marrow

Table 4 Odds ratios (ORs) and 95\% confidence intervals (Cls) for short stature in relation to rs3025020 genotypes

\begin{tabular}{|c|c|c|c|c|c|}
\hline & \multicolumn{3}{|c|}{ rs3025020 } & \multirow{2}{*}{$\begin{array}{l}p \\
\text { value }\end{array}$} & \multirow{2}{*}{$\begin{array}{l}\text { Minor allele } \\
\text { (T) }\end{array}$} \\
\hline & $(\mathrm{C} / \mathrm{C})$ & $(\mathrm{C} / \mathrm{T})$ & $(T / T)$ & & \\
\hline No. of participants & 734 & 515 & 128 & & \\
\hline $\begin{array}{l}\text { No. of cases } \\
\text { (\%) }\end{array}$ & $246(33.5)$ & $180(35.0)$ & $32(25.0)$ & & \\
\hline \multirow[t]{2}{*}{ Model 1} & & & $0.61(0.40,0.94)$ & 0.024 & $0.88(0.73,1.05)$ \\
\hline & 1 & $1.03(0.80,1.32)$ & $0.62(0.40,0.96)$ & 0.152 & \\
\hline \multirow[t]{2}{*}{ Model 2} & & & $0.59(0.38,0.91)$ & 0.017 & $0.86(0.72,1.03)$ \\
\hline & 1 & $1.01(0.79,1.30)$ & $0.59(0.36,0.93)$ & 0.103 & \\
\hline
\end{tabular}

Model 1: adjusted only for sex and age. Model 2: adjusted further for body mass index (BMI), smoking status, drinking status, triglycerides, HDL-cholesterol, $\mathrm{HbA} 1 \mathrm{c}$, and glomerular filtration rate (GFR). Short stature was defined as the lowest tertile of height $(<160.8 \mathrm{~cm}$ for men and $<148.7 \mathrm{~cm}$ for women) 
volume is positively associated with height, this positive association between height and CD34-positive cells could be caused by age-related reduction in bone marrow activity. Therefore, short stature is a risk factor for age-related reduction of bone marrow that causes tissue hypoxia. In this mechanism, VEGF expression levels could be elevated in participants with short stature, as tissue hypoxia associated with lower angiogenic activity might increase VEGF abundance [19].

However, in the present study, the minor allele homozygote $(\mathrm{T} / \mathrm{T})$ participants showed a significantly lower OR for short stature. Since the minor rs3025020 allele is reported to be positively associated with serum levels of VEGF [10], age-related reduction of bone marrow could not explain this association.

Height is generally considered a marker of social and physical conditions during childhood and adolescence [20-24], although genetic factors may also influence physical conditions during childhood (adolescence). During the growth period, VEGF plays an important role in skeletal development by stimulating angiogenesis and endochondral ossification [25, 26]. Therefore, genetic characteristics that exhibit beneficial effects on elevating VEGF [10] could result in a comparatively higher growth rate in childhood when necessary, leading to non-short stature in adulthood. However, this beneficial effect of rs3025020 on height development is only supportive; this genetic characteristic may help prevent delayed development of height in childhood, resulting in a lower prevalence of short stature but not an accelerated development of height. In the present study, homozygotes for the minor allele exhibited a significantly lower prevalence of short stature than carriers of the major allele; however, there was no significant difference between the two groups for sex-adjusted values of height. Height is affected by various genetic and environmental factors, and unknown factors might influence the observed associations. Furthermore, aging is associated with height loss [27]; in line with this notion, subjects with short stature $(75.3 \pm 7.2)$ in the present study were significantly older than those without short stature $(71.5 \pm 6.6$, $p<0.001)$. Thus, age-related height loss may have influenced the present results. However, in the present study, no significant association was observed between the minor rs3025020 allele $(\mathrm{T})$ and age. Therefore, the influence of age-related height loss is expected to be limited. Notably, we observed a significant association between rs3025020 and short stature even after adjusting for age.

Additionally, hypoxia contributes to functional degeneration during the aging process [28]; hypoxia is considered a well-known cause of hypertension [29]. Since homozygotes $(\mathrm{T} / \mathrm{T})$ of the rs3025020 minor allele may exert beneficial effects in terms of compensation for hypoxia by inducing angiogenesis, such individuals may also experience beneficial effects such as the absence of hypertension in later life.

However, we believe that rs3025020 is not a determinant factor, but one of several factors contributing to the association between hypertension and short stature. We found a significant positive association between hypertension and short stature when we limited this analysis to major allele homozygosity $(\mathrm{C} / \mathrm{C})$, where the fully adjusted OR (and 95\% CI) was 1.56 (1.09, 2.22). Agerelated hypoxia increases the possibility of angiogenesis. This genetic characteristic might influence the magnitude of response to hypoxia, which stimulates angiogenesis [30]. A previous Spanish study reported that $\mathrm{T}$-alleles in rs3025020 were less frequent in patients with chronic obstructive pulmonary disease (COPD) and were associated with a lower risk of developing the disease [31]. This study partly supports our hypothesis that the present genetic characteristics may influence the magnitude of response to hypoxia because $\mathrm{T}$-alleles in rs3025020 show beneficial effects in preventing hypoxia related to COPD. Therefore, involvement of rs3025020 could partly explain the association between hypertension and short stature. Moreover, rs3025020 and rs3025039 might play an important role in the association between hypertension and short stature. The minor allele of rs3025020 is positively associated with VEGF levels, whereas rs3025039 is inversely associated with VEGF levels [10]. Therefore, further investigation using rs3025039 data should be performed in future studies. VEGF is important for bone formation and has also been associated with osteoporosis [32]. Since short stature in elderly is likely to be associated with osteoporosis and essential hypertension can reduce bone mineral density [33], osteoporosis may have influenced the present results. However, no significant association was observed between the minor rs3025020 allele (T) and age. Therefore, we believe that the influence of osteoporosis was likely limited. Further investigations in the context of osteoporosis are necessary.

The results of the present study indicate that genetic factors that may exert beneficial effects on skeletal development during childhood could also prove to be beneficial in preventing hypertension in later life. These associations may partly explain the mechanism underlying the association between hypertension and short stature.

Potential limitations of the present study warrant consideration. Due to the shortage of serum samples, we could not evaluate serum VEGF levels, which might have influenced the present results. Further investigations surrounding these data are necessary. Owing to the limited sample size in this study, precise sex-specific analyses, especially for men, could not be performed. For women, a significant positive association between the 
minor rs3025020 allele ( $\mathrm{T}$ ) and height and a significant inverse association between the minor rs3025020 allele (T) and short stature were observed. Notably, for men, an inverse tendency (though insignificant) was observed between the minor rs3025020 allele $(\mathrm{T})$ and height. However, the OR of subjects with short stature in the context of the rs3025020 genotype (using carriers of the major allele as a reference group) for homozygotes $(\mathrm{T} / \mathrm{T})$ was $0.95(0.49,1.82)$, which is below 1 . We hypothesize that this genetic characteristic may lead to a lower prevalence of short stature but not of accelerated growth. Further studies based on larger study populations are warranted to clarify this.

\section{Conclusions}

In conclusion, with reference to the group of carriers of the major allele, homozygosity of the minor allele of rs3025020 was found to be inversely associated with hypertension and short stature, and short stature was found to be positively associated with hypertension. The capacity for angiogenesis indicated using the genetic factor (rs3025020) may partly explain the mechanism underlying the inverse association between height and hypertension.

\begin{abstract}
Abbreviations
VEGF: Vascular endothelial growth factor; OR: Odds ratio; Cl: Confidence interval; SD: Standard deviation; BMI: Body mass index; TG: Triglyceride; HDLc: HDL-cholesterol; HbA1c: Hemoglobin A1c; GFR: Glomerular filtration rate; n: Number of participants; COPD: Chronic obstructive pulmonary disease
\end{abstract}

\section{Acknowledgements}

We are grateful to staff from Goto City Hall for their outstanding support.

\section{Authors' contributions}

YS designed the study and performed the statistical analyses, interpreted the data, and drafted the manuscript or revised it. HY, SY. K, KN, FN, YuN, YH, KA, $\mathrm{YA}$, and $\mathrm{YaN}$ assisted with the design of the study, were involved in data collection, and checked the manuscript. YuN, KA, and TM participated in the study concept and checked the manuscript. TM was the general coordinator and designed the study.

\section{Funding}

This study was partly supported by Grants-in-Aids for Scientific Research from the Japan Society for the Promotion of Sciences (No. 17H03740, 18 K06448).

\section{Availability of data and materials}

We cannot publicly provide individual data due to participant confidentiality, according to ethical guidelines in Japan. Additionally, obtaining informed consent does not include a provision for publicity sharing data. Qualifying researchers may apply to access a minimal dataset by contacting Prof Takahiro Maeda, Principal Investigator, at tmaeda@nagasaki-u.ac.jp. Please contact the office of data management at ritouken@vc.fctv-net.jp. Information for where the data request is also available at http://www.med. nagasaki-u.ac.jp/cm/

\section{Ethics approval and consent to participate}

All procedures involving human participants in this study were performed in accordance with the ethical standards of the institution research committee and the 1964 Helsinki Declaration and its later amendments for comparable ethical standards. This study was approved by the Ethics Committee of Nagasaki University Graduate School of Biomedical Sciences (project registration number: 14051404). Written consent forms in Japanese were made available to ensure a comprehensive understanding of the study objectives, and informed consent was provided by the participants.

\section{Consent for publication}

Not applicable

\section{Competing interests}

The authors declare that they have no competing interests.

\section{Author details}

${ }^{1}$ Department of Community Medicine, Nagasaki University Graduate School of Biomedical Sciences, Nagasaki, Japan. ${ }^{2}$ Department of Cardiovascular Disease Prevention, Osaka Center for Cancer and Cardiovascular Diseases Prevention, Osaka, Japan. ${ }^{3}$ Department of General Medicine, Nagasaki University Graduate School of Biomedical Sciences, Nagasaki, Japan. ${ }^{4}$ Department of Islands and Community Medicine, Nagasaki University Graduate School of Biomedical Sciences, Nagasaki, Japan. ${ }^{5}$ Department of Public Health, Nagasaki University Graduate School of Biomedical Sciences, Nagasaki, Japan.

Received: 19 October 2020 Accepted: 18 January 2021

Published online: 04 February 2021

\section{References}

1. Sohn K. The association between height and hypertension in Indonesia. Econ Hum Biol. 2017:27(Pt A):74-83.

2. Song L, Shen L, Li H, Liu B, Zheng X, Liang Y, Yuan J, Wang Y. Height and prevalence of hypertension in a middle-aged and older Chinese population. Sci Rep. 2016;6:39480.

3. Takakura N, Watanabe T, Suenobu S, Yamada Y, Noda T, Ito Y, Satake M, Suda T. A role for hematopoietic stem cells in promoting angiogenesis. Cell. 2000;102(2):199-209.

4. Shimizu Y, Kawashiri SY, Kiyoura K, Nobusue K, Yamanashi H, Nagata Y, Maeda T. Gamma-glutamyl transpeptidase ( $\gamma$-GTP) has an ambivalent association with hypertension and atherosclerosis among elderly Japanese men: a cross-sectional study. Environ Health Prev Med. 2019;24(1):69.

5. Shimizu Y, Sato S, Koyamatsu J, Yamanashi H, Nagayoshi M, Kadota K, Kawashiri SY, Inoue K, Nagata Y, Maeda T. Platelets and circulating CD34positive cells as an indicator of the activity of the vicious cycle between hypertension and endothelial dysfunction in elderly Japanese men. Atherosclerosis. 2017;259:26-31.

6. Shimizu Y, Yamanashi H, Noguchi Y, Koyamatsu J, Nagayoshi M, Kiyoura K, Fukui S, Tamai M, Kawashiri SY, Arima K, Maeda T. Association between height and circulating CD34-positive cells taken into account for the influence of enhanced production among elderly Japanese men: a crosssectional study. Aging (Albany NY). 2019;11(2):663-72.

7. Shimizu Y, Sato S, Koyamatsu J, Yamanashi H, Nagayoshi M, Kadota K, Kawashiri SY, Maeda T. Possible mechanism underlying the association between height and vascular remodeling in elderly Japanese men. Oncotarget. 2017:9(8):7749-57.

8. Shimizu Y, Sato S, Koyamatsu J, Yamanashi H, Nagayoshi M, Kadota K, Maeda T. Height is an indicator of vascular maintenance capacity in older men. Geriatr Gerontol Int. 2017:17(10):1729-36.

9. Pandey AK, Singhi EK, Arroyo JP, Ikizler TA, Gould ER, Brown J, Beckman JA, Harrison DG, Moslehi J. Mechanisms of VEGF (vascular endothelial growth factor) inhibitor-associated hypertension and vascular disease. Hypertension. 2018:71(2):e1-8.

10. Al-Habboubi HH, Sater MS, Almawi AW, Al-Khateeb GM, Almawi WY. Contribution of VEGF polymorphisms to variation in VEGF serum levels in a healthy population. Eur Cytokine Netw. 2011;22(3):154-8.

11. Shimizu Y, Arima K, Noguchi $Y$, Kawashiri SY, Yamanashi H, Tamai M, Nagata $Y$, Maeda T. Potential mechanisms underlying the association between single nucleotide polymorphism (BRAP and ALDH2) and hypertension among elderly Japanese population. Sci Rep. 2020;10(1):14148.

12. Shimizu Y, Sato S, Noguchi Y, Koyamatsu J, Yamanashi H, Higashi M, Nagayoshi M, Kadota K, Kawashiri SY, Nagata Y, Takamura N, Maeda T. Impact of single nucleotide polymorphism on short stature and reduced tongue pressure among community-dwelling elderly Japanese participants: a cross-sectional study. Environ Health Prev Med. 2017;22(1):62.

13. Shimizu Y, Yamanashi H, Noguchi Y, Koyamatsu J, Nagayoshi M, Kiyoura K, Fukui S, Tamai M, Kawashiri SY, Arima K, Maeda T. Short stature-related 
single-nucleotide polymorphism (SNP) activates endothelial repair activity in elderly Japanese. Environ Health Prev Med. 2019;24(1):26.

14. Imai E, Horio M, Watanabe T, Iseki K, Yamagata K, Hara S, Ura N, Kiyohara Y, Moriyama T, Ando Y, Fujimoto S, Konta T, Yokoyama H, Makino H, Hishida A, Matsuo S. Prevalence of chronic kidney disease in the Japanese general population. Clin Exp Nephrol. 2009;13(6):621-30.

15. Levy BI, Ambrosio G, Pries AR, Struijker-Boudier HA. Microcirculation in hypertension: a new target for treatment? Circulation. 2001;104(6):735-40.

16. Brusnahan SK, McGuire TR, Jackson JD, Lane JT, Garvin KL, O'Kane BJ, Berger AM, Tuljapurkar SR, Kessinger MA, Sharp JG. Human blood and marrow side population stem cell and Stro-1 positive bone marrow stromal cell numbers decline with age, with an increase in quality of surviving stem cells: correlation with cytokines. Mech Ageing Dev. 2010;131(11-12):718-22.

17. Garvin K, Feschuk C, Sharp JG, Berger A. Does the number or quality of pluripotent bone marrow stem cells decrease with age? Clin Orthop Relat Res. 2007:465:202-7.

18. Guralnik JM, Ershler WB, Schrier SL, Picozzi VJ. Anemia in the elderly: a public health crisis in hematology. Hematology Am Soc Hematol Educ Program. 2005:528-32.

19. Ramakrishnan S, Anand V, Roy S. Vascular endothelial growth factor signaling in hypoxia and inflammation. J Neuroimmune Pharmacol. 2014; 9(2):142-60.

20. Hozawa A, Murakami Y, Okamura T, Kadowaki T, Nakamura K, Hayakawa T, Kita Y, Nakamura Y, Okayama A, Ueshima H; NIPPON DATA80 Research Group. Relation of adult height with stroke mortality in Japan: NIPPON DATA80. Stroke. 2007;38(1):22-6.

21. Honjo $\mathrm{K}$, Iso H, Inoue M, Tsugane S. Adult height and the risk of cardiovascular disease among middle aged men and women in Japan. Eur J Epidemiol. 2011;26(1):13-21.

22. Shimizu Y, Imano H, Ohira T, Kitamura A, Kiyama M, Okada T, Ishikawa $Y$, Shimamoto T, Yamagishi K, Tanigawa T, Iso H; CIRCS Investigators. Adult height and body mass index in relation to risk of total stroke and its subtypes: the circulatory risk in communities study. J Stroke Cerebrovasc Dis. 2014;23(4):667-74

23. Shimizu Y, Nakazato M, Sekita T, Kadota K, Arima K, Yamasaki H, Goto H, Shirahama S, Takamura N, Aoyagi K, Maeda T. Relationship between adult height and body weight and risk of carotid atherosclerosis assessed in terms of carotid intima-media thickness: the Nagasaki Islands study. J Physiol Anthropol. 2013;32(1):19.

24. Shimizu Y, Yoshimine H, Nagayoshi M, Kadota K, Takahashi K, Izumino K, Inoue K, Maeda T. Height correlates with dyslipidemia in non-overweight middle-aged Japanese men. J Physiol Anthropol. 2016;35(1):29.

25. Mackie EJ, Ahmed YA, Tatarczuch L, Chen KS, Mirams M. Endochondral ossification: how cartilage is converted into bone in the developing skeleton. Int J Biochem Cell Biol. 2008;40(1):46-62.

26. Hu K, Olsen BR. The roles of vascular endothelial growth factor in bone repair and regeneration. Bone. 2016;91:30-8.

27. Sorkin JD, Muller DC, Andres R. Longitudinal change in height of men and women: implications for interpretation of the body mass index: the Baltimore longitudinal study of aging. Am J Epidemiol. 1999;150(9):969-77.

28. Yeo EJ. Hypoxia and aging. Exp Mol Med. 2019;51(6):1-15.

29. Sunderram J, Androulakis IP. Molecular mechanisms of chronic intermittent hypoxia and hypertension. Crit Rev Biomed Eng. 2012;40(4):265-78.

30. Pugh CW, Ratcliffe PJ. Regulation of angiogenesis by hypoxia: role of the HIF system. Nat Med. 2003;9(6):677-84.

31. Baz-Dávila R, Espinoza-Jiménez A, Rodríguez-Pérez Mdel C, Zulueta J, Varo N, Montejo Á, Almeida-González D, Aguirre-Jaime A, Córdoba-Lanús E, Casanova C. Role of HIF1A, VEGFA and VEGFR2 SNPs in the susceptibility and progression of COPD in a Spanish population. PLoS One. 2016;11(5): e0154998.

32. Keller-Baruch J, Forgetta V, Manousaki D, Zhou S, Richards JB. Genetically decreased circulating vascular endothelial growth factor and osteoporosis outcomes: A Mendelian randomization study. J Bone Miner Res. 2020;35(4): 649-56.

33. Ye Z, Lu H, Liu P. Association between essential hypertension and bone mineral density: a systematic review and meta-analysis. Oncotarget. 2017; 8(40):68916-27.

\section{Publisher's Note}

Springer Nature remains neutral with regard to jurisdictional claims in published maps and institutional affiliations.

\section{Ready to submit your research? Choose BMC and benefit from}

- fast, convenient online submission

- thorough peer review by experienced researchers in your field

- rapid publication on acceptance

- support for research data, including large and complex data types

- gold Open Access which fosters wider collaboration and increased citations

- maximum visibility for your research: over $100 \mathrm{M}$ website views per year

At BMC, research is always in progress.

Learn more biomedcentral.com/submissions 